\title{
Relato e questões de uma pesquisa: diagnóstico sobre o PROERD
}

\author{
Report and questions of a research: evaluating PROERD \\ Marlon Leal Rodrigues ${ }^{1}$ \\ Universidade Estadual de Mato Grosso do Sul
}

\begin{abstract}
- RESUMO: O presente texto é um relato e questões de uma pesquisa de campo, elaborar um diagnóstico sobre o PROERD do Estado de Mato Grosso do Sul. A pesquisa foi e ainda está sendo um desafio, considerando que a $\mathrm{AD}$ trabalho de forma incontornável com o dado qualitativo e a PM com o dado quantitativo. Enfim, a questão metodológica foi superada em termos. Após aplicação do projeto piloto, a perspectiva é aplicar no município de Campo Grande e depois no Estado. O objetivo geral da pesquisa é analisar alguns dos efeitos de sentidos do projeto que vem sendo desenvolvido no Estado há vinte anos. Quais são as representações discursivas que o PROERD produz ou não nas atividades de prevenção, conscientização e resistências às drogas.

- PALAVRAS-CHAVE: PROERD. Drogas. Representação. Resistência. Discurso.
\end{abstract}

- ABSTRACT: The present text is a report and questions of a field research, to elaborate a evaluation on the PROERD of the State of Mato Grosso do Sul. The research was and still is a challenge, considering that the $\mathrm{AD}$ works in an incontrollable way with the qualitative data and PM with the quantitative data. Finally, the methodological question was quite overcome. After applying the pilot project, the perspective is to apply in the municipality of Campo Grande and later in the State. The general objective of the research is to analyze some of the effects of meanings of the project that has been developed in the State for twenty years. The discursive representations that PROERD produces or not in the activities of prevention, awareness and resistance to drugs.

- KEYWORDS: PROERD. Drogs. Representation. Resistence. Discourse.

O PROERD é mais um fator de proteção desenvolvido pela Polícia Militar para valorização da vida, contribuindo, assim, para o fortalecimento da Cultura da Paz e a construção de uma sociedade mais saudável e feliz (Livro do Estudante, $5^{\mathrm{a}}$. série).

\section{Introdução}

A proposta neste texto é relatar algumas questões de pesquisa de campo e suas problemáticas desde a elaboração do projeto até o momento de analisar os dados. Nas etapas do desenvolvimento do projeto, aí incluindo a proposta como desafio e seus desdobramentos de uma pesquisa diagnóstica sobre a representação discursiva do PROERD - Programa de Educação de Resistências às Drogas da Polícia Militar do Estado de Mato Grosso do Sul.

Qualquer pesquisa em si de caráter "individual" representa e possui um conjunto de tomada de posição cujo ajuste ou alteração de "sentido" (ORLANDI, 1999) pode significar de diversas formas o projeto. No entanto, quando a proposta do projeto

\footnotetext{
${ }^{1}$ Pós-doutorado pela UNICAMP. Professor Adjunto da Universidade Estadual de Mato Grosso do Sul, atua nos Mestrados Acadêmico e Profissional em Letras da UEMS. Coordenador do NEAD. marlon@uems.br
} 
circunscreve trabalho de campo, coletivo, aplicar questionários em escolas aonde o PROERD atua, envolver professores da PM. Não se trata apenas de uma pesquisa que se poderia de classificar como grande, ela se inscrever na "ordem do discurso" (ORLANDI, 2002) de desafios de políticas públicas, pois, a partir dos resultados, os professores do PROERD possuem como objetivo refletir sobre a dimensão dos resultados e no limiar das questões, propor práticas que possam redimensionar certas concepções para obter resultados satisfatórios.

Assim, a partir dessas considerações, a pesquisa visa desenvolver instrumentos metodológicos para elaborar um diagnóstico sobre o efeito de sentidos do PROERD ao longo dos dezessete anos de existência no Estado.

O objeto da pesquisa se constitui nos discursos da posição sujeitos de ex-alunos do Programa, professores da escola e do PROERD, alunos do quinto ano ao terceiros ano do ensino médio, e ainda alunos da quarta série, que ainda não tiveram contato com o PROERD.

O objetivo geral é elaborar um diagnóstico sobre a atuação do Programa cuja finalidade é poder mensurar em que medida a prática discursiva e não discursiva tem produzido efeitos de sentido sobre os sujeitos que participaram dos cursos e das atividades, ou seja, em que medida o Programa produz efeitos tais que os sujeitos na posição de aluno em sua vida escolar e pós-escolar não se deixam interpelar em alguma medida pelo uso de produtos lícitos e ilícitos ou que medida resistem a eles.

Assim, para se chegar ao diagnóstico discursivo, temos os seguintes objetivos específicos como "procedimentos metodológicos" (RODRIGUES, 2007):

- analisar o funcionamento discursivo considerando a posição sujeito da comunidade escolar: alunos, ex-alunos (de outras séries), professores, coordenação pedagógica e direção em relação ao Programa;

- analisar o funcionamento do discurso de ex-alunos (fora da escola ou que já concluíram o ensino médio) e também de instrutores do PROERD e sua historicidade;

- analisar em que medida o Programa interpela os alunos para a prevenção de usos de produtos lícitos e ilícitos;

- analisar como se constitui a representação discursiva "objetos e temas" do PROERD da comunidade escolar, não escolar (pais) e instrutores (policiais);

- procurar desenvolver instrumentos para análise em duas perspectivas: uma pontual, dos ex-alunos, e outra, progressiva, com a aplicação de questionários contínuos por semestre.

O corpus discursivo são "textos" (ORLANDI, 2012) dos "questionários discursivos" (RODRIGUES, 2011) diferenciados entre si considerando os sujeitos e suas respectivas posições. A elaboração do questionário possui um caráter qualitativo incontornável para a Análise do Discurso.

\section{Breve Histórico do PROERD}

O PROERD - Programa Educacional de Resistência às Drogas e à Violência atua no segmento da prevenção primária sendo uma versão brasileira do programa DARE (Drug Abuse Resistence Education) criado em 1983 em Los Angeles, nos Estados Unidos e segundo Constantino (2007), após a realização de estudos acerca de dados estatísticos de ocorrências de uso e tráfico de drogas entre crianças e adolescentes daquela cidade, o Departamento de Polícia de Los Angeles - EUA chegou à conclusão 
de que a atividade repressiva da força policial não estava atingindo a eficiência esperada. A partir deste momento, o Departamento de Polícia juntamente com o Distrito Escolar de Los Angeles, criou sob a supervisão e coordenação da pedagoga Ruth Rich, o DARE (Drugs Abuse Resistance Education), utilizando material didático adequado à realidade das crianças da faixa etária de 9 a 12 anos de idade.

Os resultados positivos repercutiram e geraram grande interesse em outras cidades norte-americanas, tanto que, em 1986, 48 departamentos de polícia enviaram seus homens a Los Angeles para serem treinados e em 1987, 398 departamentos de polícia de 33 estados dos Estados Unidos já acompanhavam o programa (BRUNETTA, 2006, p. 65).

Atualmente, 60 países do mundo aplicam o programa, sob os mais variados nomes (FOSTER, 2014), no entanto, todos baseados no modelo norte-americano e utilizando material didático com algumas modificações adaptadas à realidade e especificidade de diferentes países. Anualmente são formadas aproximadamente 30 milhões de crianças em todo o mundo.

O DARE chegou ao Brasil em 1992 no estado do Rio de Janeiro, com o nome PROERD - Programa Educacional de Resistência às Drogas e à Violência. Já no estado de Mato Grosso do Sul o Programa foi implantado em 1997, conseguindo reconhecimento como política educativa de relevante interesse para a segurança pública, conforme Lei estadual $\mathrm{n}^{\mathrm{o}} 3.845$, de 10 de fevereiro de 2010.

O PROERD em Mato Grosso do Sul desde sua implantação já atendeu mais de 223 mil alunos em todo o estado (conforme Tabela 1). Especificamente na cidade de Campo Grande, no ano de 2013, foram atendidas 27 escolas municipais, 02 particulares e 13 estaduais, totalizando mais de 3.424 novos proerdianos ${ }^{2}$ formados. Partindo do ano de 2009, é possível verificar um aumento significativo do número de crianças atendidas pelo Programa na capital de MS (ver Tabela 2).

TABELA 1: Dados estatísticos do Proerd em Mato Grosso do Sul até 2013

\begin{tabular}{|l|l|}
\hline $\begin{array}{l}\text { Número de Policiais Militares Instrutores do PROERD } \\
\text { no MS }\end{array}$ & $\begin{array}{l}89 \text { (oitenta e nove) Instrutores do } \\
\text { PROERD atuantes }\end{array}$ \\
\hline $\begin{array}{l}\text { Número de municípios atendidos pelo Programa do } \\
\text { PROERD }\end{array}$ & 66 (sessenta e seis) municípios \\
\hline Municípios não atendidos pelo Programa do PROERD & 13 (treze) Municípios \\
\hline \multicolumn{1}{|c|}{ TOTAL DE ALUNOS ATENDIDOS PELO PROERD/MS } \\
\hline Rede Estadual & 66.476 alunos \\
\hline Rede Municipal & 144.235 alunos \\
\hline Rede particular & 8.171 alunos \\
\hline Total Geral de Alunos atendidos & 223.234 alunos \\
\hline \multicolumn{2}{|c|}{ TOTAL DESCOLAS ATENDIDAS PELO PROERD/MS } \\
\hline Rede Estadual & 1.121 escolas \\
\hline Rede Municipal & 2.032 escolas \\
\hline Rede Particular & 230 escolas \\
\hline Total Geral de Escolas atendidas & 3.383 escolas \\
\hline
\end{tabular}

Fonte: Coordenadoria Estadual de Resistência às Drogas de Mato Grosso do Sul CERD MS

As estatísticas apresentadas na Tabela 1 com a quantidade de alunos e escolas que já foram atendidas pelo programa desde sua implantação em 1997 até o ano de 2013 demonstram dados importantes sobre a quantidade do público atendido pelo programa,

\footnotetext{
${ }^{2}$ Assim são chamados com muita alegria e carinho os alunos que fizeram ou estão fazendo o PROERD.
} 
no entanto, não abrangem as demais necessidades de avaliação voltadas aos principais de dados seja realizada, conforme afirmação de Jannuzzi:

Os indicadores guardam, pois, relação direta com o objetivo programático original, na forma operacionalizada pelas ações e viabilizada pelos dados administrativos e pelas estatísticas públicas (2005: 137)

Por conseguinte, as estatísticas do programa no estado de MS, não têm dado conta de registrar a eficácia do mesmo, pois conforme a Tabela 2 não há um levantamento minucioso que verifique em que medida o Programa consegue “interpelar" (PÊCHEUX, 2002) a posição sujeito aluno para prevenção ao uso de produtos que provocam dependência psíquica e/ou orgânica.

TABELA 2: Dados estatísticos do PROERD na cidade de Campo Grande/MS de 2009 a 2013

\begin{tabular}{|c|c|c|c|c|}
\hline \multirow{2}{*}{ Ano } & \multicolumn{4}{|c|}{ TOTAL DE ALUNOS } \\
\cline { 2 - 5 } & Estadual & Municipal & Particular & Total \\
\hline $\mathbf{2 0 0 9}$ & & & 66 & 7275 \\
\hline $\mathbf{2 0 1 0}$ & 1302 & 5907 & & 7367 \\
\hline $\mathbf{2 0 1 1}$ & & & 158 & \\
\hline $\mathbf{2 0 1 2}$ & 1302 & 5907 & & \\
\hline $\mathbf{2 0 1 3}$ & & & & \\
\hline
\end{tabular}

Fonte: Coordenadoria Estadual de Resistência às Drogas de Mato Grosso do Sul CERD MS

Nesta perspectiva é que o presente projeto almeja a fundamentação de dados, para a comprovação da eficácia do trabalho realizado pela prevenção através de técnicas e ferramentas que possibilitem um melhor gerenciamento de seus resultados.

\section{Programa Educacional de Resistências às Drogas}

Analisar a "discursividade" (ORLANDI, 2002) sobre o PROERD que foi implantado, desde 1997, no Estado de Mato Grosso do Sul pela Polícia Militar. O Programa consiste em ministrar nas escolas públicas - estaduais municipais e em algumas escolas particulares - cursos de prevenção e "conscientização", informação e esclarecimentos de "posição sujeito" (ORLANDI, 2008) alunos do quinto ano ${ }^{3}$ do ensino fundamental sobre o uso de produtos que causam dependência psíquica, orgânica e psíquica, como o uso de cigarros, bebidas e entorpecentes, ou seja, drogas ilícitas ou não.

Analisar o "discurso" (ORLANDI, 2012) de Programa a partir da posição sujeito aluno, professores, e ex-alunos implica elaborar questões que possa criar um roteiro enquanto suporte discursivo de problematizações que seja possível analisar o funcionamento dos discursos e seus efeitos, ou seja, em que medida a discursividade PROERD interpela o sujeito na posição aluno? Esta questão permeia a pesquisa.

Se a pesquisa de campo e suas questões colocam diferenciadas, este aspecto também impõe instrumento e prática metodológica que possa diagnosticar o efeito de sentido sobre a posição sujeito de aluno ao longo dos dezessete anos de desenvolvimento PROERD, ou seja, em que medida o Programa consegue interpelar a

\footnotetext{
${ }^{3}$ É importante ressaltar que o PROERD atua também com outros currículos, sendo eles: Educação infantil e anos iniciais do ensino fundamental e PROERD para Pais.
} 
posição sujeito aluno para prevenção ao uso de produtos que provocam dependência psíquica e/ou orgânica e qual ou quais os sentidos desta interpelação.

Há um discurso do senso que o "conhecimento e saber" garantem o "fazer", no entanto o "saber" discursivo para produzir efeitos de sentidos nas práticas discursivas e não discursiva, precisa produzir certos efeitos, o que não ocorre de forma linear, nesse aspecto, é importante ressaltar que a relação entre conhecimento e o saber sobre o fato do mundo não implica automaticamente em "práticas não discursivas" (PÊCHEUX, 1997) pelo efeito de sentido que transforme esse saber, pois, se o "sujeito individuado" (ORLANDI, 2012) é constituído simbolicamente o que decorre conceber que

\begin{abstract}
a linguagem como mediação necessária entre o homem e a realidade natural e social. Essa mediação, que é o discurso, torna possível tanto a permanência e a continuidade quanto o deslocamento e a transformação do homem e da realidade em que vive. O trabalho simbólico do discurso está na base da produção da existência humana (idem, 199, p. 15).
\end{abstract}

A relação entre práticas discursivas e práticas não discursivas não ocorrem de forma simétrica em seus sentidos, como se fosse uma mera transmissão de conhecimento e saber, tanto o discurso quanto a prática são constituídas de efeitos de sentidos cuja possibilidade de criar "lastro" de identificação depende, em certa medida, das "condições de produção do discurso" (ORLANDI, 1997) e da historicidade dos sujeitos em condições materiais de existência. Por mais que se queira "regrar, selecionar, controlar" a materialização discursiva, algo fala antes, conforme concebe Orlandi (2014, p. 72):

o Outro como presidindo o jogo com o real da História, aquilo que não pode ser assim, a memória discursiva como incontornável na constituição dos sujeito e dos sentidos. O Já-dito presente em todo dizer, o sempre já lá.

O próprio gesto de selecionar, controlar e regrar já vem significado não pelo gesto do sujeito ou seu "processo de subjetivação" (ORLANDI, 2012), mas pelo real da história e da língua inscritos em determinada formação discursiva e não em outra. Pois, o gesto não garante o processo de identificação, pois, de acordo com Pêcheux (2002, p. 56) "não há identificação plenamente bem sucedida, isto é, ligação sócio-histórica que não seja afetada, de uma forma ou de outra, por uma "infelicidade" no sentido performativo do termo". Isso implica que apenas a circulação do discurso não garante que ele produza um efeito de sentido "esperado" em todos aqueles que ele interpela, no entanto, pode-se considerar que somente na/pela circulação e "insistência" das práticas discursivas enquanto processo educativo pode assegurar a possibilidade e não a garantia dos efeitos de sentidos esperados, visto que há formas diversas de "formulações" (ORLANDI, 2002) e jogos de "paráfrases" (ORLANDI, 1999).

A circulação, enquanto processo educativo, de qualquer discurso marca sua existência enquanto possiblidade de certos efeitos de sentido e não outros, cujas condições de produção e circulação concorrem e disputam com outros discursos em espaços de coexistência, pois, a existência de um discurso supõe outros com os quais disputa espaços e sujeitos a interpelar, dito de outra forma no caso do Programa, a existência do discurso do PROERD vem disputar espaços de existência no combate dos discursos sobre os usos de produtos lícitos e ilícitos, ou seja, um discurso que interpela sujeitos em várias idades para o consumo destes produtos, o que historicamente tem gerado sentido de problema social de degeneração e degradação da integridade física e psíquica dos sujeitos. 
Vale ressaltar que estes sentidos não são homogêneos e que há o contradiscurso que usos de substâncias lícitas e ilícitas que não causam dependência física e psíquica e nem tão pouco problema de saúdo pública de degeneração física e psíquica e ainda mesmo que o sujeito em sua posição de usuário ou possível usuário reconheça o discurso da ciência como na ordem discursiva da autoridade, isto também não tem garantido o não uso, ou seja, não produziu efeito de sentido porque outros discursos em seu entorno "venceram".

A existência do Programa possui o sentido de prevenção, de disputa, de conquista como uma das formas de combater o uso e tráfico de produtos ilícitos. Procura produzir também sentidos ainda em sujeitos em idade escolar na expectativa que haja certa identificação que possa criar um tipo "consciência" política de resistência aos outros discursos cujo efeito é exatamente o oposto, sentido de adesão ao uso e consumo de produtos lícitos e ilícitos, ou seja, drogas.

Nesse sentido, é importante ressaltar que a constituição do sujeito é marcada pela "incompletude" (ORLANDI, 2002, 2012) da existência, "sempre" com se estivesse em uma busca de uma completude, uma busca do impossível, ou modos de subjetivação como forma de vivenciar sensações, emoções, sentimentos etc., como se estivesse preenchendo "algo" que falta ou ainda como vivenciar "aventuras" diversas ao marcar posição em grupo ou individual.

O uso de produtos lícitos e ilícitos, por seus efeitos quer no uso ritualístico em grupo ou individual acaba por "dar" esse sentido de sensação de completude, experenciar no/pelo sujeito, mesmo que o custo psíquico e orgânico seja a degeneração e degradação do sujeito em sua posição de usuário, ou como se chama no "discurso do cotidiano" (RODRIGUES, 2011), viciado, drogado ou dependente de drogas, caso das ilícitas ou viciado em consumo de fumo e álcool, no caso das lícitas.

É importante ressaltar que o discurso do "politicamente correto" se presta a amenizar certos sentidos, o que equivale a tentar deslocar certos sentidos indesejados, de visibilidade das práticas não discursivas sociais, colocando sujeito em um espaço de sentido, talvez um tanto mais confortável. Exemplos:

- de drogado para viciado e deste para dependência psíquica ou química e ainda para usuário de substância química, e mais recentemente, consumidor recreativo;

- de bêbado para alcóolatra;

- viciado em cigarro para fumante e deste para dependente, e ainda de dependência psíquica ou física para consumidor.

Convém ressaltar que se o sujeito foi pego com uma quantidade de "produtos ilícitos", pode discursiviza que é para uso e consumo próprio ou recreativo que ameniza a sua prática, pois ele é consumidor.

\section{Procedimentos Metodológicos: um desafio}

A proposta, incialmente, foi apresentada como um desafio ao NEAD, considerando que a Análise do Discurso trabalha na perspectiva teórica de um quadro conceitual qualitativo, o que não demanda tabelas, gráficos, cálculos, estimativas para compreender de alguma perspectiva o fato do mundo em sua existência significante quantitativa. A posição foi de declinar da proposta, pois, para a Polícia Militar a tabulação de dados por faixa etária, série, escola, região onde a escola se situa exalunos, policiais envolvidos no PROERD, pais de alunos, escola etc. é uma questão de lugar de interpretação dos dados, das ocorrências quantitativas que determinam as 
escolhas e decisões sobre ações de prevenção e/ou repressão. Ou seja, uma pesquisa nos parâmetros positivistas que contempla e orienta ações.

Após algumas explicações e discussões sobre análise qualitativa, chegou ao acordo da importância da perspectiva da Análise do Discurso, no entanto, seria um dado "novo" que talvez o PROERD tivesse alguma dificuldade de trabalhar com ele e de como poderia contribuir para políticas de prevenção e intervenção enquanto espaço efetivo. A falta do dado quantitativo fragiliza ações e programas, visto que é impossível atender a todas as demandas de uma vez só.

Ainda, neste sentido, precisaria de número, dados quantitativos para orientar opções de ação do Estado. Eis o desafio, pensar o dado qualitativo que o PROERD passa interpretar também como quantitativo sem deslizamento e nem mudança de território e nem tão pouco de uma estranha junção, ou qualquer "puxadinho teórico" (ORLANDI, 2002: p. 25). Pêcheux (1997: p. 304) vem ao socorro quanto: "é preciso ousar", seria bom se fosse sem risco.

O NEAD aceitou o projeto e o desafio. Iniciou-se um período de reflexão e desespero, muito mais este do que aquele. Aos poucos com leituras e discussão dentro de um quadro de possíveis soluções, desenhou-se um horizonte em que fosse possível desenvolver a pesquisa e atender também a necessidade de dado quantitativo para o PROERD.

Ressalto que as pesquisas que tenho desenvolvido, sempre teve uma quantidade de corpora significativa em termos que quantidade de "textos" para análise. Estava em um lugar de observador das paráfrases, das repetições, de deslocamentos, das transformações em outro, das contradições, das rupturas, dos aparecimentos e desaparecimentos de sentidos, posições ideológicas, dos lugares das condições de produção dos discursos; observando as formações discursivas e suas formas de constituição, suas movências, tentando compreender o sujeito e seu modo de funcionamento etc. Isto diante de apreensões - no mestrado, no doutorado, e pósdoutoramento ${ }^{4}$ - de mais de mil "textos" já apreendido para análise. Era e ainda é um quadro "gigantesco" de material, ficar observando-os, elaborando questões para eles, questionando o que faz com que eles sejam o que são.

Esta prática tem sido o lugar de conforto também para orientandos e "companheiros" de orientação. Tentando refletir sobre como poderia trabalhar os dados quantitativos sem abandonar o campo, sem deserção, sem distorção e nem distensão, posição impensável. Aos poucos um quadro de possibilidade foi se formando.

Assim, os procedimentos metodológicos foram se configurando, a primeira posição foi considerar o "texto" (ORLANDI, 1984) enquanto dado discursivo de caráter material de um lado e de caráter qualitativo, de outro. Foi necessário desenvolver procedimentos e recursos metodológico para analisar os dados em duas perspectivas: $\mathrm{o}$ qualitativo e o quantitativo. $\mathrm{O}$ dado em sua perspectiva quantitativa se presta apenas para verificar as circulação dos discursos, suas ocorrências e quais representação estão inscritas e quais subjaz a elas. O que não representa que a quantificação possa determinar sentidos outros, mas observar em que medida certos dados discursivos podem ou não inscrever nessa ou naquela "ordem do discurso" (ORLANDI, 2011), ou ainda, a quantidades de ocorrência ou ausência delas possa significar.

Alguns conceitos como "paráfrase, texto, discurso" (ORLANDI, 1999) e "questionário discursivo" nortearam toda questão metodológica e analítica. Sobre o

\footnotetext{
${ }^{4}$ Nestes períodos de formação trabalhava com o conceito de enunciado, no entanto, após leitura do texto de Orlandi (1984) sobre "Recortar ou Segmentar", a noção de "recorte e texto" supera metodologicamente a de enunciado para Análise do Discurso.
} 
questionário discursivo, uma reflexão ainda por terminar, muito embora nos últimos dez há um conjunto de trabalhos orientadas com esta proposta, há demandas de sentidos por acabamento teórico. Ressalta-se que talvez seja no conjunto de aplicações enquanto testagem se possa ao longo do tempo chegar a uma síntese.

Diante da problematização qualitativo com possibilidade de quantificá-lo, foi desenhado o seguinte quadro com desafio:

- analisar a discursividade de todas as escolas do Estado de Mato Grosso do Sul onde há atuação do PROERD. Vale ressaltar que há práticas discursivas regulares específicas em determinadas condições de produção e em outras não. Em relação ao Estado, há uma diversidade formações etnicor-raciais em constante movimento: indígena, negros, europeus e mais recentemente os asiáticos. Pode-se ainda ressalta vasta região de fronteira externa;

- para testagem do questionário, foi escolhida uma escola ${ }^{5}$ de piloto de Campo Grande, a escolha ficou por conta da Polícia Militar, pois, foi feito a partir de dados peculiares para a Polícia;

- a proposta de envolver Policiais Militares na pesquisa foi uma reflexão importante, o que gerou uma dissertação mestrado, uma monografia de especialização (CB/PM Dienny Graciely Souto de Souza Melo). Isto representa que a pesquisa também está qualificando ou formando-os não apenas para esta a pesquisa, mas para outras. Na contra partida, foi importante para o NEAD compreender a leitura do dado qualitativo na dimensão das práticas sociais e suas opacidades que o dado quantitativo por si só não consegue abranger;

- corpus será a partir do questionário discursivo adequado a faixa etária e ano, antes e depois do contato com o PROERD, policiais militares que atuam no PROERD, ex-aluno do ensino médio, pais de alunos, comunidade escolar (diretora, coordenadora pedagógica, administrativo e profissional de apoio). Há uma questão significativa sobre aplicação de questionário em menores que requer autorização dos pais e da escola. Por se tratar de uma pesquisa diagnóstica do próprio PROERD, a autorização não se faz necessário;

- a elaboração do questionário no. 01 (apenas para alunos) foi realizada após diversas discussões, narrativa e material do próprio PROERD (cartilha e relatório). O questionário foi revisto e finalizado com todos os membros da equipe antes de ser aplicado;

- perfil do questionário: cabeçário, ficha, ano, termo de uso, identificação do aluno como voluntária, dezessete perguntas, espaço de cinco linhas apenas para responder;

- qualificação dos membros da equipe para trabalho de campo: pesquisadores, policiais, alunos da graduação (bacharelado e licenciatura) e a própria equipe do NEAD. Discussões sobre o quadro conceitual da Análise do Discurso;

- preparação para trabalho de campo, relatórios das aplicações, informações sobre a escola (bairro, nível social, ocorrências diversas etc.). Um ponto muito discutido, qual seria percentual de alunos que seria aplicado, cinquenta por cento (50\%) foi o número;

- ritual de aplicação do questionário como elemento metodológico de relevância. Não comentar com alunos a respeito do que se trata o questionário, não esclarecer o responder nada sobre o questionário, avisar que colocar o nome é 5 Escola Municipal Brígida Ferraz Foss, bairro Jacy. A aplicação do questionário foi feita por três (03) em
25/11/2015, como já foi dito, alunos da graduação, professores do PROERD e professores do NEAD. 
voluntário, que deve ler tudo o questionário antes de responder, pedir que o aluno, depois de terminado de responder, colocar o questionário no envelope em cima da mesa;

- além das perguntas o que mais constar: nome, idade, sexo, religião, bairro, se mora com os pais ou outros, se há alguém na família fuma ou usa droga ilícita;

- foi desenvolvido um termo de sigilo para todos os participantes (Laís Rigolin Chaves, Marlene Eliane dos Santos, Noany Vieira Candido de Barros, Viviani Cavalcante de Oliveira, Leite, Everton Rodrigues Simões, Aline Werlang Soares, Elifalete da Silva, Angela Maria Félix, Fernando Ramos Campos, Lorrayne Marques de Lima, Talita de Almeida Paula, Márcia Aparecida da Cruz Silva, Mayra Mayquelle de A. Suzano, Mayara Nascimento Alexandre) sobre o que se poderia encontrar nos questionário, resguardar o sigilo. Neste ponto, foi levantada a seguinte questão: se algum aluno ou membro da comunidade escolar fazer alguma denuncia ou insinuar sobre violência sexual, simbólica e outras, qual seria a posição a Universidade? Ofertar ou não a denuncia? Após longas discussões, chegou-se a seguinte decisão que ainda está em fase de reflexão. A Universidade não oferecerá denúncia, pois, como há membros da Polícia Militar atuando em todas as etapas da pesquisa, o questionário será destruído e a Polícia Militar sem envolver a pesquisa e a Universidade, irá encaminhar atividades com pedagogos, psicólogos e Serviço Social e Reservado para verificar se procede ou não a denúncia. Esta questão causou um pouco de comoção no grupo pelos supostos sentido inscritos nos questionário;

- procedimentos de análise:

a) as perguntas discursivas para o momento da análise são desconsideradas a não ser que a resposta discursiva remeta à pergunta discursiva, quando ocorre, a pergunta é colocada em nota rodapé;

b) a pergunta discursiva "provoca" a inscrição da discursividade. Selecionar os "textos" (ORLANDI, 1989) relacionados com as questões e problematização da pesquisa. O conceito de paráfrase é fundamental;

c) diante a totalidade das respostas, o analista em seu gesto, seleciona somente aquilo que se presta para sua análise de classificação (ver entre barras nos exemplos a seguir), não se esquecendo que toda análise e classificação possui uma instabilidade. Se mudar de pergunta ou questão, os sentidos podem ser outro, se inscrever em outros discursos. Exemplo:
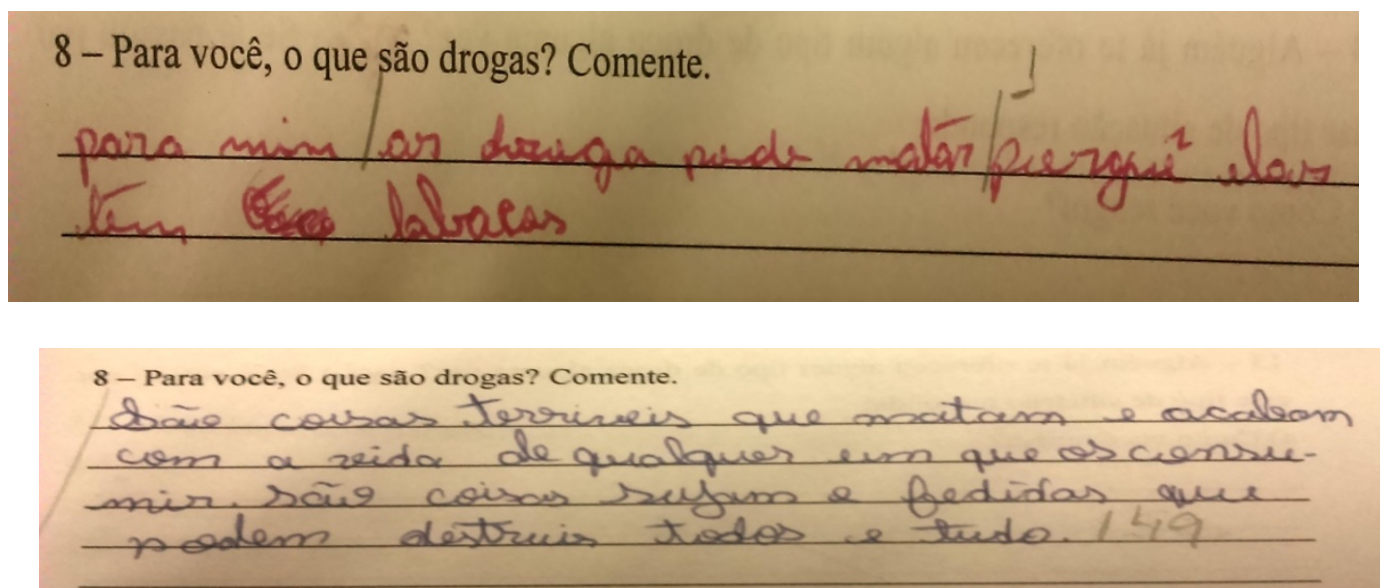
d) o conjunto texto foi agrupado em discursos na medida em que um era paráfrase do outro de forma que pertenciam a um mesmo discurso e formações discursivas. O conjunto foi classificado em discursos. É um momento importante, pois um mesmo texto se presta há diversos discursos;

e) foi agrupadas todas as paráfrases discursivas em um mesmo discurso (já dito no tópico anterior), ou seja, em todo os questionário foram registradas as ocorrências dos textos e contamos as repetições. Foram aplicados trezentos e quatorze questionários (314) em (25/11/2015); dez (10) turmas: uma (01) quarta ano $\left(4^{\circ}.\right)$, duas quinto ano $\left(5^{\circ}\right)$, uma sexto $\left(6^{\circ}.\right)$, duas sétimo ano $\left(7^{\circ}.\right)$, duas oitavo ano $\left(8^{\circ}\right.$.), e duas nono ano $\left(9^{\circ}\right.$.); recortados três mil trezentos e vinte e noves (3.329) textos agrupados e quarenta e cinco (45) discursos;

f) o conjunto de texto e suas paráfrases representaram também um conjunto de discursos. Para exemplificar apresentamos três tipos de discursos e suas paráfrases:

\section{Discurso Sobre a Representação de Drogas}

(360) "Drogas são elementos muitos ruins para a nossa saúde e também para a nossa família." (F. O1, p. 02, $5^{\circ}$ ano A, 11/2015);

(377) "Drogas destro vidas" (F. O2, p. 02, 50 ano A, 11/2015);

(394) "Drogas são: Doenças causadas por coacina crack e outros tipos de drogas" (F. O3, p. 02, 5" ano A, 11/2015);

(409) "Droga pra mim é veneno porque ela faz mal pro nosso corpo." (F. O4, p. 02, 50 ano A, 11/2015);

(422) "uma coisa ruim porque faz mal" (F. O5, p. 02, 5 ano A, 11/2015);

(434) "É uma coisa que não e permitida, ela faz muito mal e pode causar até a morte” (F. O6, p. 02, $5^{\circ}$ ano A, 11/2015);

(449) "É uma coisa sem futuro para mim" (F. O7, p. 02, 5' ano A, 11/2015);

(453) "as drogas são porcarias" (F. O7, p. 03, 5 ano A, 11/2015);

(463) "Drogas para mim bem o próprio nome já diz mas eu acho que droga é estragar sua vida." (F. O8, p. $02,5^{\circ}$ ano $\left.\mathrm{A}, 11 / 2015\right)$;

(484) "as drogas são uma coisa que deixa a cara doida." (F. O9, p. 02, 5 ano A, 11/2015);

(493) "não prejudiciais a saúde decaba com sua vida" (F. 10, p. 02, 5 ano A, 11/2015);

(502) "são muito ilegais, deixa a gente doido, Viciado e etc" (F. 11, p. 02, 50 ano A, 11/2015);

(513) "uma coisa muito ruim pra saúde, destrói sua vida, Ema droga literalmente" (F. 12, p. 02, 5 ano A, $11 / 2015)$;

(524) "Eu acho que drogas é a pior coisa que pode acontecer na sua vida" (F. 13, p. 02, 5 ano A,

$11 / 2015)$;

(534) "drogas são efeitos toxco eu nuca quero fumar" (F. 14, p. 02, $5^{\circ}$ ano A, 11/2015);

(541) "isso é muito errado" (F. 14, p. 05, $5^{\circ}$ ano A, 11/2015);

(550) "para mim ção um nocho" (F. 15, p. 03, 5 ano A, 11/2015);

(561) "Drogas são para mim um negócio muito ruim e também pode destruir familías. (F. 16, p. 02, 5 ano A, 11/2015);

(563) "uma é mais fortes e a outra nem tanto forte.”(F. 16, p. 03, 5 ano A, 11/2015);

(582) “Drogas são muito mal para a saúde.”(F. 18, p. 03, 5 ano A, 11/2015);

(588) "Coisas que faz muito mal, você pode ficar maluco pode até morrer se ficar mexendo com drogas." (F. 19, p. 03, $5^{\circ}$ ano A, 11/2015);

(603) "uma coisa muito ruim prejudica sua saúde" (F. 20, p. 02, 5 ano A, 11/2015);

(616) "Drogas é aguma coisa que mata" (F. 21, p. 03, $5^{\circ}$ ano A, 11/2015);

(628) "uma coisa ruim que visia as pessoas" (F. 22, p. 02, $5^{\circ}$ ano A, 11/2015);

(639) "Drogas para mim, são remédios ou outras drogas que contenham substâncias que fazem mal à saúde, mas os remédios são drogas permitidas" (F. 23, p. 03, 5 ano A, 11/2015);

(655) "São coisas ruins que não faz bem para a saúde" (F. 24, p. 03, $5^{\circ}$ ano A, 11/2015);

(665) "Porcaria" (F. 25, p. 03, 5\% ano A, 11/2015);

(675) "uma coisa que nunca vo usa" (F. 26, p. 02, 5 ano A, 11/2015);

(690) "São um feneno muito perigoso que pode matar pode causar câncer de boca que são as drogas licidas" (F. 27, p. 03, $5^{\circ}$ ano A, 11/2015). 
- Destacamos quatro textos $(360,394,449,588)$ que representam o discurso como enunciados de base, os demais não serão analisados, são apenas para amostragem quantitativa.

\section{Discurso Sobre os Efeitos das Drogas}

(361) "Causa tonturas, mal estar, dor de cabeça" (F. O1, p. 03, 50 ano A, 11/2015);

(378) "causa mal estar e tontura" (F. O2, p. 03, 50 ano A, 11/2015);

(381) "a pessoa fica muito loca" (F. O2, p. 03, $5^{\circ}$ ano A, 11/2015);

(383) "as pessoas não ve o que a drogas faz na sua vida" (F. O2, p. 04, 50 ano A, 11/2015);

(395) "Causam doenças como: câncer no pulmão pode apodrecer seu dentes pode acontecer acidentes."

(F. O3, p. 03, $5^{\circ}$ ano A, 11/2015);

(410) "câncer de pumão, tontura e falta de respirar" (F. O4, p. 02, 5 ano A, 11/2015);

(423) "causa varias doenças" (F. O5, p. 03, 5 ano A, 11/2015);

(435) "Elas ficam violentas, desorientada, doente, passa muito mal ele perde sua vergonha." (F. O6, p. $03,5^{\circ}$ ano $\left.A, 11 / 2015\right)$;

(438) "a pessoa usa drogas ail ela fica desorientada" (F. O6, p. 04, 5\% ano A, 11/2015);

(450) "Sim violência, cansaso e etc" (F. O7, p. 03, 5' ano A, 11/2015);

(464) "Tontura, perda de coordenação, agumas provoca falta de ar." (F. O8, p. 03, 5 ano A, 11/2015);

(494) "causa perda do raciocínio sem controle do corpo e câncer de pulmão" (F. 10, p. 03, $5^{\circ}$ ano A,

$11 / 2015)$;

(503) “deixam nós viciados e fica doida" (F. 11, p. 03, $5^{\circ}$ ano A, 11/2015);

(514) “Alucinações naúse, perda do racionio, sem controle do corpo e câncer de pulmão" (F. 12, p. 02, $5^{\circ}$ ano A, 11/2015);

(516) "vários países tem muito drogas" (F. 12, p. 04, 5 ano A, 11/2015);

(525) "Deixa você tonto e com vontade de brigar" (F. 13, p. 03, $5^{\circ}$ ano A, 11/2015);

(527) "as drogas causa efeito que não são legai” (F. 13, p. 03, $5^{\circ}$ ano A, 11/2015);

(535) "toce muito dores e você comesagospir muito" (F. 14, p. 03, 50 ano A, 11/2015);

(551) "tomtura, desgasto de energia e pode matar" (F. 15, p. 03, 50 ano A, 11/2015);

(553) "as drogas fazem perder a cabeça." (F. 15, p. 04, 50 ano A, 11/2015);

(562) “Tontura, falta de ar, câncer no pulmão e etc.”(F. 16, p. 03, 5 ano A, 11/2015);

(583) “Eles fica loucos, separ a família e virá mendingo."(F. 18, p. 03, 5 ano A, 11/2015);

(589) "Sei que deixa a pessoa maluca e pode morrer."(F. 19, p. 03, 50 ano A, 11/2015);

(603) "uma coisa muito ruim prejudica sua saúde" (F. 20, p. 02, 5 ano A, 11/2015);

(617) "pode matar ou ter cançer" (F. 21, p. 03, 5 ano A, 11/2015);

(629) "tontura, falta de ar,canser e etc." (F. 22, p. 03, 5 ano A, 11/2015);

(649) "saber as doenças que podem acontecer." (F. 23, p. 06, 50 ano A, 11/2015);

(656) "causa dor de cabeça pode ater morrer e vários outras coisas." (F. 24, p. 03, 5 ano A, 11/2015);

(666) "causa muita lesões e fica querendo mais." (F. 25, p. 03, $5^{\circ}$ ano A, 11/2015);

(669) "por que decha loco." (F. 25, p. 06, 5ano A, 11/2015);

(691) "câncer de boca dos pumoês e pode matar." (F. 27, p. 03, 5 ano A, 11/2015).

- Destacamos quatro textos $(381,435,503,598)$ que representam o discurso como enunciados de base, os demais não serão analisados, são apenas para amostragem quantitativa.

\section{Discursos sobre PROERD}

(370) "o proerd ensina a resistir as preções" (F. O1, p. 05, 5' ano A, 11/2015);

(388) "me ajuda a me previni" (F. O2, p. 06, $5^{\circ}$ ano A, 11/2015);

(432) "nos ajuda muito" (F. O5, p. 06, 5 ano A, 11/2015);

(497) "para termos um futuro consiente sobre as drogas" (F. 10, p. 04, 5\% ano A, 11/2015);

(498) "temos a consciência de que as drogas são ruins" (F. 10, p. 04, $5^{\circ}$ ano A, 11/2015);

(499) “dizer não as drogas e fazer a escolha certa” (F. 10, p. 05, $5^{\circ}$ ano A, 11/2015);

(500) "nos ajuda a tomar as decisões certas" (F. 10, p. 05, 50 ano A, 11/2015);

(517) "Para termos consiente sobre as drogas" (F. 12, p. 05, 50 ano A, 11/2015)

(530) "Eu aprendi a me defender diante de problemas" (F. 13, p. 06, 5' ano A, 11/2015); 
(543) "eu estou preparado pra tudo" (F. 14, p. 05, 50 ano A, 11/2015);

(545) "ele meincinou muitas coizas" (F. 14, p. 05, 50 ano A, 11/2015);

(554) "aprendi muito no proerd."(F. 15, p. 04, $5^{\circ}$ ano A, 11/2015);

(557) "lá euposso aprender"(F. 15, p. 07, $5^{\circ}$ ano A, 11/2015);

(636) "previni as drogas"(F. 22, p. 06, 50 ano A, 11/2015);

(652) "me ensinou coisas que eu não sabia"(F. 23, p. 07, 5 ano A, 11/2015);

(658) “ela ensina a não seguir os caminhos das drogas que é ruim”(F. 24, p. 05, 50 ano A, 11/2015);

(662) “o proerd já me ajudou ver que não é bom drogas"(F. 24, p. 06, $5^{\circ}$ ano A, 11/2015);

(663) “drogas não é legal”(F. 24, p. 07, 5 ano A, 11/2015);

(698) "para aprender mais"(F. 27, p. 06, 5० ano A, 11/2015);

(701) “muito importante"(F. 27, p. 07, $5^{\circ}$ ano A, 11/2015).

- Destacamos quatro textos $(370,499,530,658)$ que representam o discurso como enunciados de base, os demais não serão analisados, são apenas para amostragem quantitativa.

g) a questão de recortar e quantificar as paráfrases e agrupá-las em discursos diferentes, não implica em uma análise diferenciada, possibilita compreender a inscrição dos textos e o que as mais diversas paráfrases podem significar. De uma outra posição, esta questão metodológica propicia ainda calculo matemático e elaborar quadros de ocorrência;

h) o total de texto foi classificado em "Y" discursos, considerando que um mesmo texto é classificado em outros discursos e contado também. Cada discurso possui "x" ocorrência de textos. A questão é: do total de textos, qual é o percentual deles em cada discurso? E o que possa significar. É a partir destes dados que se monta a fórmula matemática para fazer as tabelas e gráficos para a PM abstrair suas reflexões em termo de ocorrência discursiva por escola e o que a ocorrência por oferecer em termos de regularidade e singularidade, considerando $o$ diagnóstico vai ser por cada escola;

i) ao classificar o discurso com " $\mathrm{X}$ " textos, analisa-se os textos mais significativos de cada discurso que pode ser individual ou em conjunto. O quantitativo é reduzido ao qualitativo sem perda. Temos o seguinte:

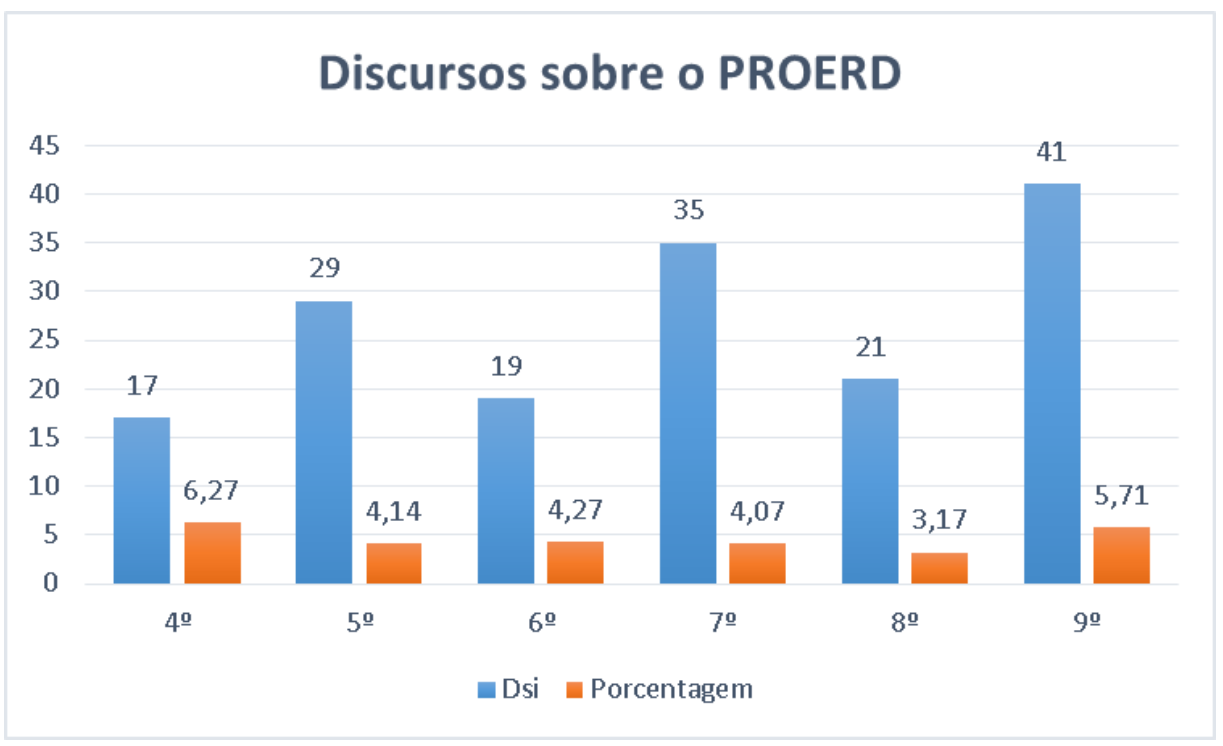

Total de textos recortados em todos os questionários: 3.329

Total de discursos classificados em todos os questionários: 45

Total de ocorrência de textos nos discursos (azul) por série 
Cor laranja, percentual de ocorrência no discurso a partir do total geral dos textos

$\bullet$

Para os professores do PROERD é significativo saber o tipo de sentido que os alunos constroem dele em diversas séries para se possa ter um retorno dos efeitos de suas práticas.

j) as inúmeras paráfrases e discursos representadas em tabela e gráficos contemplam a problemática colocada pela Polícia Militar. Os dados serão tabelas e gráficos, lidos e interpretados a partir de instrumentos próprio do PROERD, no entanto, considerando análise qualitativa de cada discurso.

\section{Considerações Finais}

A etapa piloto esta fase de finalização apenas um dos aspectos do projeto, a discursividades dos alunos do PROERD, ainda dos professores do PROERD, dos professores da escola, e dos ex-alunos. Os dados foram organizados, recortados, classificados, tabulados, o estágio atual é o de análise que está em andamento.

No processo de manuseio com os dados, sem finalização ainda, já é possível constatar sentidos os e discursos que poderá contribuir para a reflexão da atuação do PROERD.

A fase piloto encerra-se em agosto. A perspectiva é que a partir de setembro a pesquisa aplicada em todas as escolas de Campo Grande e qualificando mais equipes para aplicar no Estado.

\section{REFERÊNCIAS}

BRUNETTA, Antonio Alberto. Autoridade policial na escola. São Paulo: Editora Junqueira\&Marin, 2006.

CONSTANTINO, Gelson Luiz. O que é o Proerd. Polícia Militar do Paraná, 2007.

FOSTER, A.R. Combate às drogas: a importância da ampliação do Proerd na educação básica. Unilins - Universidade de Lins/SP, 2013.

JANNUZZI, Paulo de Martino. Indicadores para diagnóstico, monitoramento e avaliação de programas sociais no Brasil*. Revista do Serviço Público Brasília 56 (2): 137-160 Abr/Jun 2005.

MATO GROSSO DO SUL (Estado). Lei N $\mathrm{N}^{\mathrm{3}} 3.845$, de 10 de fevereiro de 2010. Reconhece o Programa Educacional de Resistência às Drogas e à Violência (PROERD) como política educativa de relevante interesse para a segurança pública e dá outras providências.

ORLANDI, E. P. Discurso em Análise. Sujeito, sentido, ideologia. Campinas-SP: Pontes, 2012.

. Análise do Discurso. Princípios e Procedimentos. Campinas-SP: Pontes, 1997. $\overline{2001}$.

Discurso e Texto. Formulação e Circulação dos Sentidos. Campinas-SP: Pontes,

PÊCHEUX, M. O Discurso. Estrutura ou Acontecimento. 3ª Ed. Campinas-SP: Pontes, 2002.

Semântica Discursiva. Uma afirmação do óbvio. Campinas-SP: Pontes, 1997.

PROERD. Uma Escola de Cidadania para a Vida. 5. Ano. Livro do Estudante. Secretária de Segurança Pública. S/D. 
RODRIGUES, M. L. Discurso de Representação do Negro Cotista da UEMS. Tese de Pós-Doutoramento, UNICAMP - Universidade Estadual de Campinas. Campinas-SP, 2011, mímeo.

. Complexo de Objeto e de Temas: condições de produção do discurso. In

(org.) Linguagem, Identidade, Gênero, História. Rio de Janeiro-RJ: Litteris Ed., 2011. P. 49-64

MST: Discurso de Reforma Agrária pela Ocupação. Um acontecimento discursivo. Tese de Doutoramento (Doutor em Linguística), UNICAMP - Universidade Estadual de Campinas-SP, 2007.

Recebido em: agosto de 2017.

Aprovado em: dezembro de 2017.

Como citar este trabalho:

RODRIGUES, M. L. Relato e questões de uma pesquisa: diagnóstico sobre o PROERD. Traços de linguagem, v. 2, n. 1, p. 8-21, 2018. 